\title{
Polimedia: Using advanced \\ screencasting for effective e-learning content production
}

\section{Carlos Turró}

Head of Media Services

Universidad Politécnica de Valencia

\section{Manuel Jiménez}

Researcher

Área de Sistemas de Información at Universidad Politécnica de Valencia

\section{Luis Morcillo}

Researcher

Área de Sistemas de Información at Universidad Politécnica de Valencia

\section{Jaime Busquets}

Head of IT department

Universidad Politécnica de Valencia
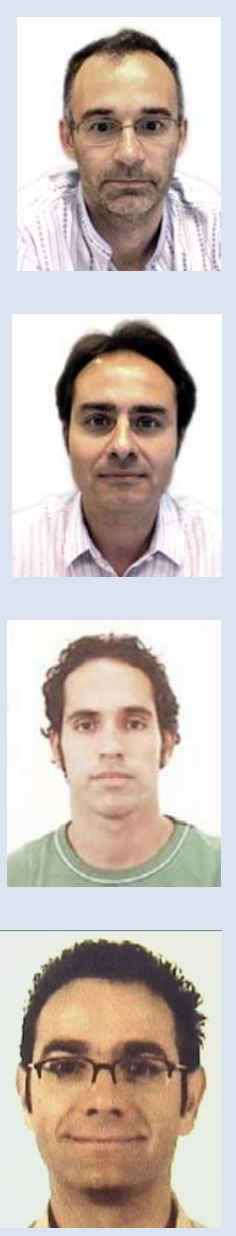
Carlos Turro is the Head of Media Services at the Universidad Politécnica de Valencia. He received his M.Sc. and Ph.D. in Communications Engineering in 1992 and 2003, respectively. His work deals with the delivery of media content on the Computer Network of the University and to the Internet. His research centers on the applications of Media Services in mobile devices and wireless networks.

Manuel Jimenez is the main researcher for Media Services in the Area de Sistemas de Información of the Universidad Politécnica de Valencia. He has led the TELDE project, dealing with the distribution of video e-learning courses over a satellite network. Currently his research interests are on the development of elearning services for big audiences.

Luis Morcillo is a researcher for the Area de Sistemas de Información of the Universidad Politécnica de Valencia since 2005. He has participated in the TELDE project, dealing with the distribution of video e-learning courses over a satellite network. Currently his research interests are in the field of integration of video and streaming services on e-learning products.

Jaime Busquets is the Head of IT Department at the Universidad Politécnica de Valencia. He has published several papers on elearning and IT Services. Currently he is focusing on researching about the organizational issues of IT departments for large institutions.

\section{Abstract}

In this paper we present Polimedia, a system designed to help teachers producing high quality e-learning content without technological knowledge. We achieve this by using a special TV-like recording studio that gets teachers' video and learning material in a way that resembles standard 
slide presentations. We present the architecture of the system and we provide examples and results of its usage at Universidad Politecnica de Valencia, where we have used this system with more than 200 teachers and 2,500 recording tracks.

\section{Polimedia: Using Advanced Screencasting for effective e-learning content production}

Traditional teaching experience is a mixture of different kinds of inputs, such as voice, non-verbal communication (teachers' gestures), projection screen, blackboard, showing different objects, etc.). The transmission of this set of senses through technological platforms is not easy, due to the great number of items that are lost along the way. Moodle, Sakai, and other platforms contain tools to present text and graphical objects, as well as communication tools and assignments, but do not include multimedia systems except simple links to videos. As we had those needs, we developed Polimedia, a system designed to create multimedia content easily synchronized with slide shows, live demonstrations, or a screen of a software application. Polimedia is a standard-based e-learning technology that has been designed to expand the capabilities of e-learning platforms with these new features.

In the development of Polimedia, the educational requirements for both the teacher and the student have been analyzed in detail, including which elements of the system can cause fatigue in users and the capabilities of reusing materials. This has led to a restructuring of reusable standardsbased learning objects, and integrated with repository tools like DSpace, allowing teachers to use the same digital objects for different editions, courses or subjects. Furthermore, Polimedia objects can be accessed from networked PCs, mobile phones, and IPod devices.

So, Polimedia is both an implementation and a way of using information technologies to enhance learning in higher education. This project combines innovation, pedagogy, and technology as key factors for creating more effective and engaging learning. At Universidad Politécnica de Valencia we use Poimedia jointly with our Sakai e-learning platform, while Polimedia can be used with any other e-learning platform, like Moodle. Today 2814 Polimedia objects have been created by 228 different teachers on 6 dedicated production studios. All of these objects can be accessed through the Sakai e-learning platform of the university, extending its capabilities. We will see some examples in this paper, but there is also more content at the URL http://polimedia.upv.es/polimedia (primarily in Spanish).

We developed Polimedia for a project aimed to give e-learning lessons in South America through the use of a Satellite link. In that project the main 
constraint was that we could not move teachers to all South America locations, so we worked on a way to transmit the "teaching experience" in a natural way.

Compared to current developments, there are not any similar solutions to Polimedia in the sense that they simultaneously cover multimedia, pedagogical, and e-learning fields. It is easy to see that YouTube or other popular solutions based on streaming media are appropriate to broadcast a movie or a home video, but do not support the text-based contents properly, or do not have the resolution or streams at the same time than images of teacher and the learning contents without post-production, like Polimedia does. Furthermore, utilities such as Adobe Connect or Camtasia do not cover the importance of the teacher and educational structures, and focus only on the transmission of slides narrated without added value.

The rest of the paper is organized as follows: first we will review the architecture of the Polimedia System, and we will provide some examples of its usage. Then we will address the pedagogical issues involved on it and we will show some results on its usage. Finally we will provide some insight concerning the follow-up paths of Polimedia.

\section{System Architecture}

Polimedia is a system designed for on-demand e-learning. So, as viewed in Figure 1, we bring teachers to a specially designed recording studio, and there we record both teachers' image and computer screen and we mix them in such a way that is suitable for both e-learning and successful streaming. Then we use a standard streaming server to distribute the content asynchronously to the students.

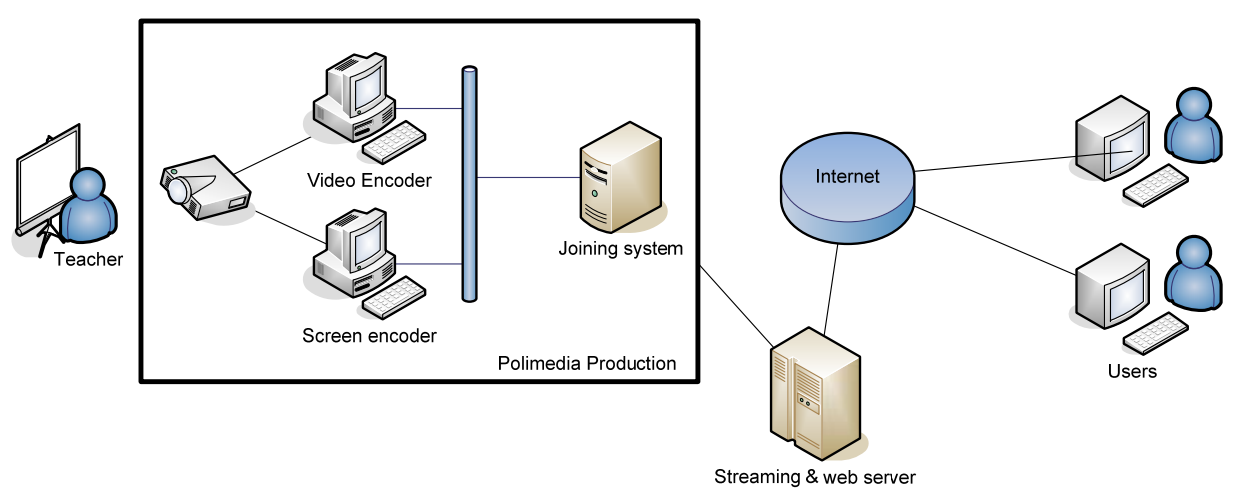

Figure 1. System Architecture

Thus, on the final product we have two windows on the PC screen. An example can be seen in Figure 2. On the right hand side is the teacher's 
image captured with a resolution of $384 \times 600$ pixels and 25 frames per second, and at the left hand side is the PC's image captured at a $800 \times 600$ pixels resolution and 5 to 10 frames per second. Both streams are synchronized.

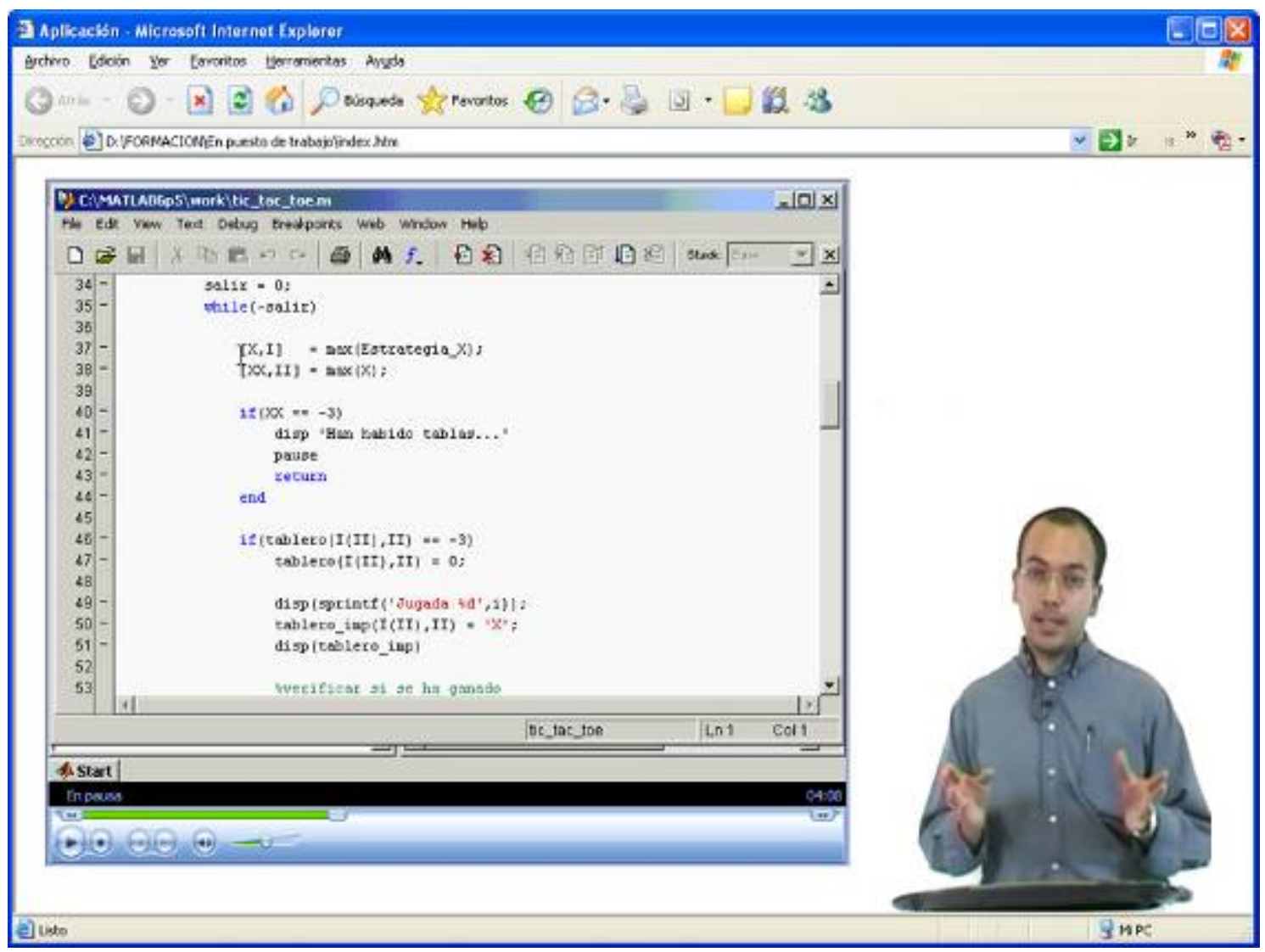

Figure 2. Polimedia object

So, the left hand side is specially designed for slowly moving content, like slides and computer demos, but can also display live video at a low frame rate. The use of this low frame rate allows us to use a lossless video codec to achieve sharp images of the computer screen or, in the case of using a lossy codec to achieve more compression ratio, use a set of video compression parameters that allow us to maintain such video quality. On the other hand, the teacher's video is compressed using a standard lossy codec that provides us with smooth movement and a high compression ratio.

In Figure 3 you can see an example of Polimedia live embedded on this file. 


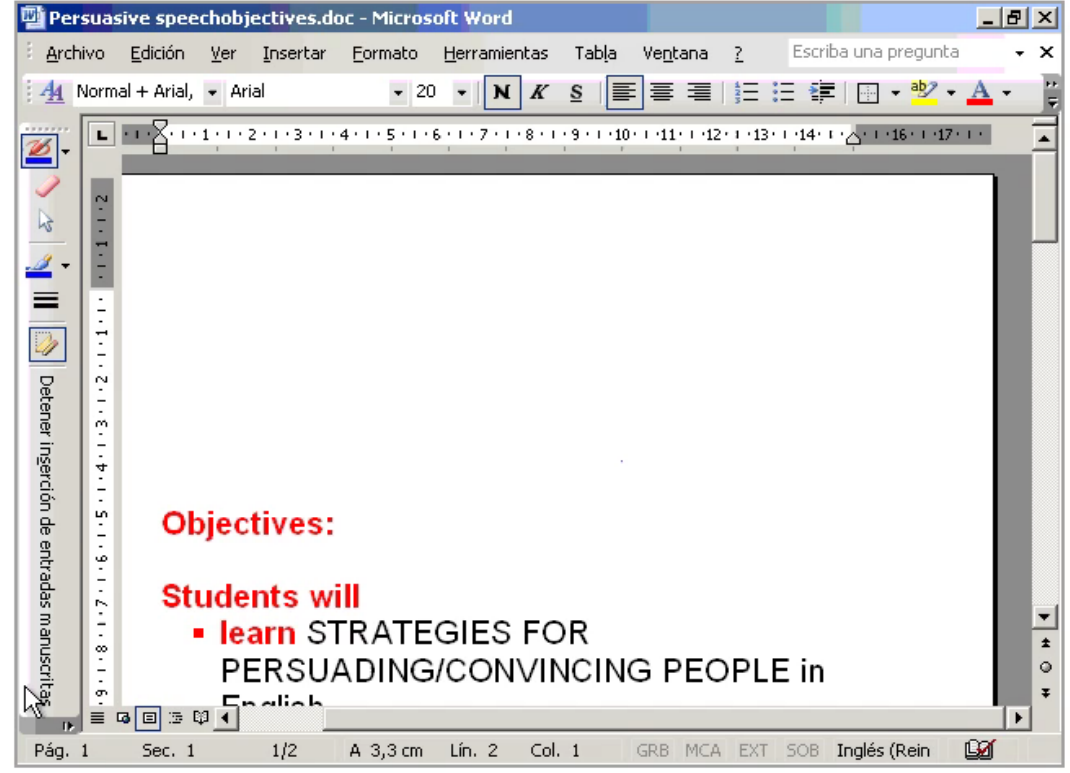

Figure 3. Example of Polimedia embedded

From the teacher's point of view, recording a Polimedia object is as easy as arriving with a Powerpoint file, a laptop, or even a URL to our recording studio. There are two screens, one at the front of the teacher, and one on the right hand side. In such a position he or she will record the lesson, and both streams will be recorded. In Figure 4 and 5 you can see the setup for the studio and an image of a live recording.

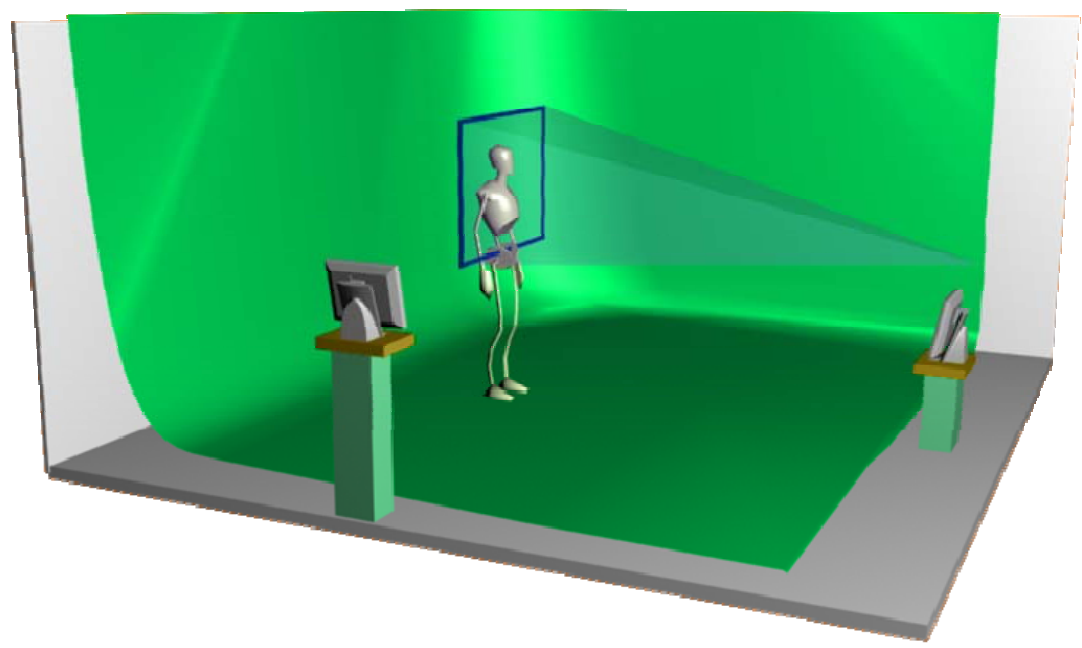

Figure 4. Teacher set-up 


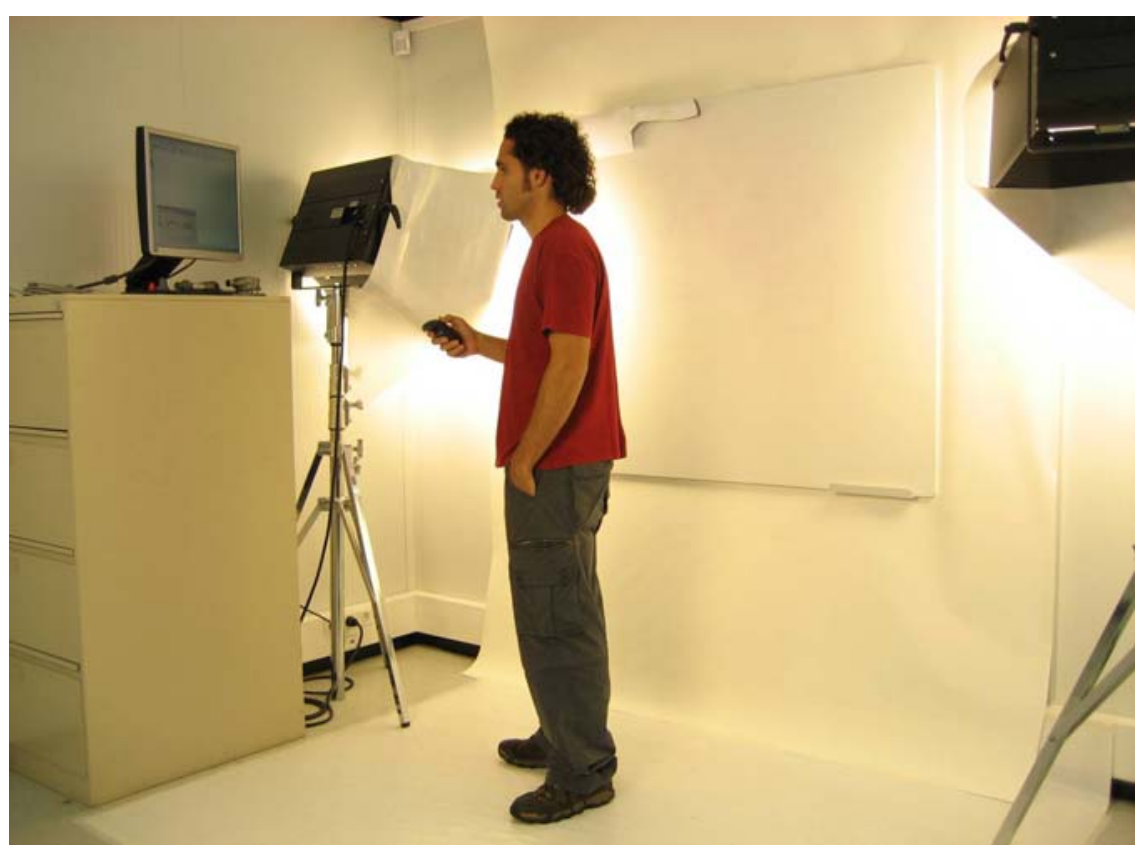

Figure 5. Live recording

\section{Pedagogical Aspects and Usage Results}

The Polimedia system belongs to asynchronous training e-learning category using the Learning Objects (LO) paradigm. As defined by (Wiley, 2005), a LO is the minimum unit of digital learning content that can be reused and sequenced. So these small components should work like integrated circuits of the teaching-learning process, offering the students the possibility to improve their performance and level of satisfaction.

Then, the determination of the features of the learning objects facilitates the establishment of some appropriate approaches of their validation, and at the same time it will help in assuring the quality in their creation. So a LO should have or be:

1) Digital format: A LO should be usable from Internet and accessible simultaneously for many people and from different places.

2) Pedagogic purpose: the objective is to assure a process of satisfactory learning. Therefore, LO will not only include contents but rather also guide the own process of the student's learning.

3) Interactive content: A LO should encourage as much as possible the active participation in the information interchange. Then a LO should tend to include activities (exercises, simulations, questionnaires, charts, graphics, slides, tables, exams, experiments, 
etc.) that allow to facilitate the process of assimilation and the tracking of each student's progress.

4) Indivisible and independent of other learning objects, so we can make different learning sequences for one LO, depending on the student or the objectives.

5) Reusable in educational contexts different from what the original was created for. This feature is the one that determines that an object has value, being one of the starts that base the concept of learning object. For a LO to be reusable, it is necessary that there is not any reference to their location in any particular course neither in the subject nor in the course. Also a LO requires a series of metadata to describe its content. We use SCORM as a standard for that.

By using the LO paradigm, we structure the course in modules and then in lessons, as seen on Figure 6. Each lesson will address just one concept.

\begin{tabular}{|l|l|l|l|l|l|}
\hline Lesson 0 Introduction & $\approx 5 \mathrm{~min}$ \\
\hline MODULE & $\approx 10-20 \mathrm{~min}$ \\
\hline Lesson 1 & $\approx 10-20 \mathrm{~min}$ \\
\hline Lesson 2 & $\approx 10-20 \mathrm{~min}$ \\
\hline Lesson 3 & $\approx 5 \mathrm{~min}$ \\
\hline Lesson 4 Conclussion & $\approx 5 \mathrm{~min}$
\end{tabular}

Figure 6. Course structure

In order to get evidence of usefulness for Polimedia we have focused on two indicators, the overall usage of all Polimedia content, and a course taught in two simultaneous instances, one with Polimedia and one with a live teacher.

For the first one, as can be seen in the next graph (Figure 7), Polimedia usage is constantly increasing, especially from the beginning of this academic course. We believe in this indicator as reference from both the students and the teachers' side. 


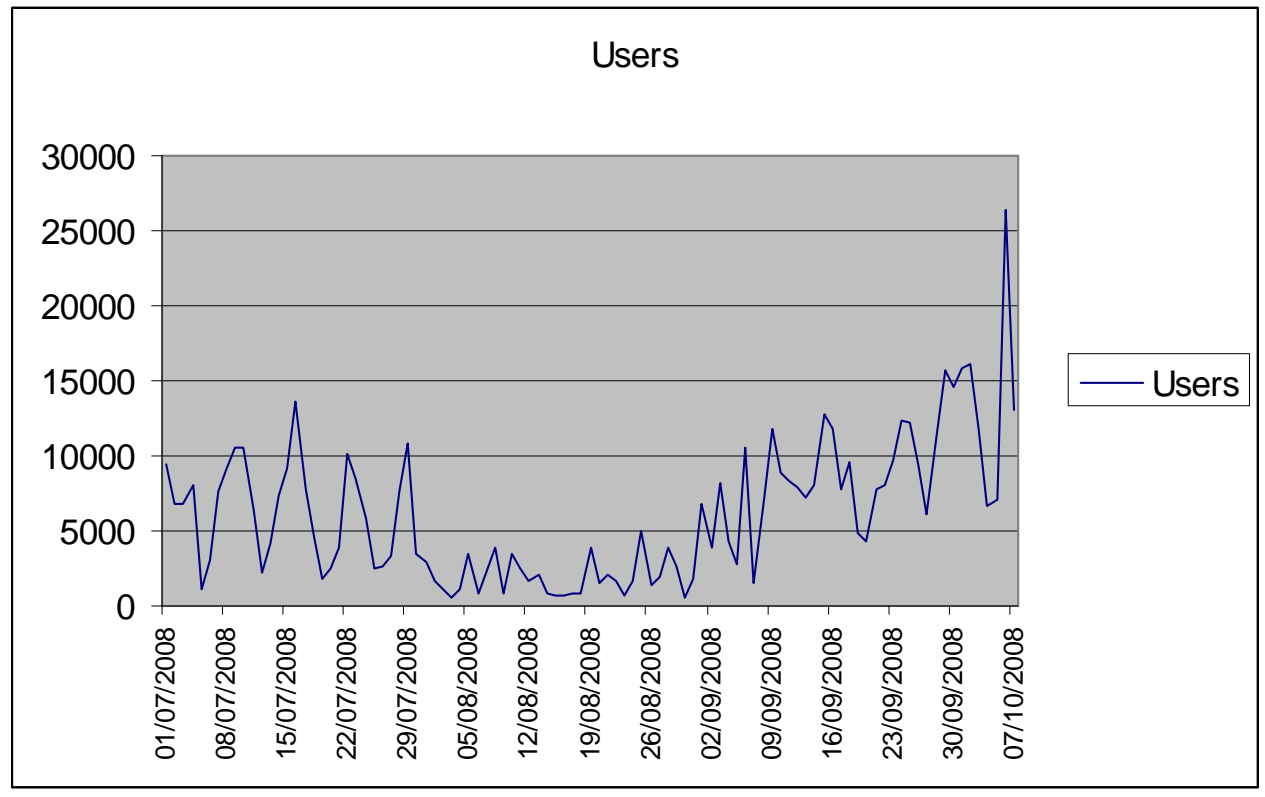

Figure 7. Polimedia usage

For the second one, we recently gave a Microsoft Excel course between November and December 2008 to a group of students with the same teacher, syllabus and overall duration (with Polimedia you can replay the teacher's explanation as you wish). Results for this experience are very similar in both cases, even having a little preference for Polimedia, as can be seen on Table 1.

\section{Classical learning Blended learning}

with Polimedia

I have reached $90 \%$ $90 \%$

knowledge objective

for this course

Course lenght is

appropiate for Course content

Teacher's course can be considered as a good teacher

I wish I would have more presential sessions 
My expectations for

$80 \%$

$85 \%$

this course have been

satisfied

Table 1. Polimedia compared to classical learning

\section{Future work}

Last year we started to disseminate Polimedia technology to other universities and e-learning projects. Currently we have deployed Polimedia at 4 Spanish universities, and we are focusing on getting 4 more before the end of this year. Also we have contacts with some European universities, and we are willing to support deployment at those universities. Finally we are putting Polimedia on the AVICENA project, funded by the UNESCO, willing to provide e-learning to all African countries.

Also we can give feedback about how Polimedia is used in Latin America. The Universidad Politécnica de Valencia uses Polimedia to provide elearning to that continent, and we have a strong tie with Mexico, where we are successfully fulfilling some e-learning needs.

On the other hand we are continuing the development of the Polimedia system. Currently we are focused on video compression, to achieve more quality using the same bandwidth, and here we are exploring some new capabilities of MP4 codec. On the pedagogical side, we wish to launch a broader test of our teaching scheme in the second half of 2009.

\section{Reference}

Wiley D. (2005) Learning objects: conditions for viability. Journal of computer assisted learning vol.:21 iss:5 